\title{
Gender Differences In Reaction To The Compromising Of Ethical Integrity And Shared Values
}

\author{
Susan G. Rozensher, (Email: erozensher@iona.edu), Iona College \\ P. Everett Fergenson, Iona College
}

\begin{abstract}
While marketing firms, and the related marketing literature, have devoted a great deal of attention to the cultivation of relationships between companies or organizations and their consumers/supporters, the issue of relationship dissolution has been largely neglected by comparison. The present study is an attempt to address this neglect by bringing into focus certain factors that may contribute to the dissolution of strong relationships between organizations and their supporters. In particular, this study will examine gender differences in the dissolution of such relationships.
\end{abstract}

\section{INTRODUCTION}



hile marketing firms, and the attendant marketing literature, have devoted a great deal of attention to the cultivation of relationships between companies or organizations and their consumers/supporters, the issue of relationship dissolution has been largely neglected by comparison (Perrin-Martinenq, 2004; Rees and Gardner, 2003; Rowley and Dawes, 2000). The present study is an attempt to address this neglect by bringing into focus certain factors that may contribute to the dissolution of strong relationships between organizations and their supporters. In particular, this study will examine gender differences and their role in the dissolution of such relationships.

The notion that women are more likely than men to view certain questionable business practices as unethical has received considerable support both in the popular press and in academic circles. Indeed, many studies, as well as a review of 66 studies (Franke et al, 1997), have found evidence for the claim that women are more likely to make ethical decisions than men (Bendall-Lyon and Powers, 2002; Glover, 2002; Kelly, 1990; Petty and Hill, 1994; Sankaran and Bui, 2003). However, such differences as a function of gender have not been uniformly supported by the literature. Specifically, in a recent cross-cultural study involving six countries, gender did not prove to be a significant predictor of consumers' reactions to various unethical consumer behavior scenarios (Babakus et al, 2004). Similarly, gender was not found to have an impact on the moral reasoning process that predicted intention to act in an ethical dilemma (Izraeli and Jaffe, 2000). The present study attempts to reexamine the controversial issue of gender differences within the context of business ethics and relationship dissolution by comparing the intended relationship behavior of males versus females as a function of changes in an organization's purported values and ethical behavior.

In order to understand the threats that can unravel a strong relationship between and organization and its supporters, we will draw upon theories of social identity and organizational identification as described in a recently proposed conceptual framework (Bhattacharya and Sen, 2003). The authors argue that strong identification with a company or organization derives from the relationship's ability to help satisfy some of the consumers' or supporters' vital self-definitional needs. In the process of constructing their identities, people self-categorize themselves in part by identifying with a company or organization that provides a good match with their own defining characteristics such as personality, values, and demographics (Ashford and Mael, 1989; Dutton, Dukerich and Harquail, 1994; Pratt, 1998). People's self-definitional needs, which include the need for self-enhancement (satisfied in part by 
identifying with prestigious companies or organizations); the need for self-distinctiveness (satisfied in part by identifying with companies or organizations that are distinctive and unique on dimensions that the consumer values), and the need for self-continuity (the need to express more completely their particular traits and values), are satisfied to some degree through this relationship with the company.

Based on this model of identification with an organization, and with particular reference to relationship dissolution, we designed a study to test the reactions of consumers/supporters when confronted with certain situations that we expected to have a destabilizing effect on their strong identification with an organization. In particular, we examined the role of gender in these circumstances.

\section{METHODOLOGY}

To ensure that the sample used for this study consisted of consumers who were highly identified with the company, we selected study participants from the population of members of a nonprofit organization, in this case, a public radio station in a large metropolitan area. These radio station members can be considered strongly identified with the organization by virtue of their behavior; that is, they had voluntarily chosen to pay the station membership fee when, in fact, they could have received access to the radio station's broadcasts for free. Similarly, it has been argued elsewhere that membership in nonprofit organizations (such as museums, theatres, and universities) is an appropriate basis for studying company or organization identification (Bhattacharya, Rao, and Glynn, 1995).

We selected the sample based on a probabilistic sampling technique known as systematic sampling, using the list of current station members provided by the radio station as our sampling frame. The radio station members were interviewed by telephone.

We took two separate measures of the members' satisfaction levels with the station. In addition, we measured station members' likelihood to renew their membership a) under current conditions, b) when shared values were diminished, and c) when the ethical integrity of the radio station had been compromised, as described below.

Demographic information was collected for the entire sample, covering the gender, education, income, and age of respondents, as well as other background information. There was a nearly even break in the number of male and female respondents, and the sample proved to be a highly educated one.

\section{HYPOTHESES}

\section{Loss Of Shared Values}

We presented our study participants with two hypothetical situations, both of which were designed to present a challenge to our participants' strongly held identification with the radio station. In the first scenario, consumers were asked for their reaction to a situation in which the radio station, with which they were known to identify strongly, accepted financial backing from a company said to behave ethically but support causes not in agreement with the radio station member's values. We hypothesized that this scenario, which represented a significant loss of shared values with the radio station and a concomitant loss of satisfaction of the station members' self-definitional needs, would lead the study participants to experience a rather negative reaction and to report a significantly increased likelihood to dissolve their relationship with the company (as measured by likelihood to renew membership on a five-point scale). Furthermore, we expected this negative change in attitude toward membership renewal to be greater among women than men.

\section{Lapse In Ethical Integrity}

The second scenario was designed to represent a more extreme case of the loss of shared values in the form of a lapse in ethical integrity. Study participants were asked for their reactions to a scenario in which the radio station, with which they were known to identify strongly, had accepted financial backing from a company that had engaged in some unethical practices. We hypothesized that, in accordance with the Bhattacharya and Sen (2003) 
framework, consumers would be even more likely than in the first scenario to report a significantly increased intention to dissolve their relationship with the company (as measured by their likelihood to renew their membership on a five-point scale). This scenario, in which the company's ethical integrity had been compromised, can be considered a clear breach of the "zone of tolerance" (Bhattacharya and Sen, 2003). We also hypothesized that women would be more inclined than men to pull back their support for the radio station, i.e. to express a more sharply diminished likelihood to renew their membership.

\section{RESULTS}

We took a baseline measure of the respondents' likelihood to renew their yearly membership as an indication of customer loyalty. The results revealed an extremely high level of likelihood to renew. When viewed separately for men and women, the mean likelihood to renew was 4.20 for the men (on a five-point scale, with 5 being Very likely to renew) and 4.56 for the women, a significant difference $(\mathrm{p}<.05)$. These results demonstrate that the women in this sample have a stronger intent to continue their relationship with the organization than the men, though both groups show a very strong intent on a five-point scale. We also took two different measures of satisfaction of members with the radio station (satisfaction with the way the radio station has treated its members, and the way the radio station has used its revenues from membership fees). Both measures found the members to be a highly satisfied group.

After establishing a baseline for likelihood to renew, we tested to see how likely respondents would be to renew their membership in two hypothetical scenarios. In one scenario, designed to test reaction to a loss in shared values with the radio station, we asked the respondents to use a five-point scale to rate their likelihood to renew their membership. Overall, when compared with their baseline likelihood to renew their membership, the respondents reported a significantly lower likelihood to renew their memberships if they were to experience a loss of shared values, and an even lower likelihood to renew if an unethical company were to provide financial backing for the organization.

In the scenario designed to test reaction to a loss in shared values with the radio station, the women's mean decline from the baseline measure in likelihood to renew was 1.35 , while that of the men was .70; the difference between the two means was significant $(\mathrm{p}=.01)$. In the other scenario, in which a company that has engaged in some unethical practices became a financial backer of the radio station, female station members' mean likelihood to renew their membership declined significantly more than that of the male station members (1.96 versus $1.23 ; \mathrm{p}<$ .01). An examination of the change scores showed important differences between the male and female station members with regard to the role of ethical integrity in determining customer support. That is, initial support of the organization was found to diminish significantly when the organization's values changed from those of its supporters, and when its ethical integrity was compromised. This effect was more pronounced among the women in the study.

\section{DISCUSSION}

Differences related to gender that emerged in the results of this study suggest a heightened reactivity among women both to a loss of shared values with an organization and to lapses in an organization's ethical behavior. Specifically, intention to continue to support the radio station through membership renewal was found to erode more seriously among women than among men not only when the ethical standards of the organization were compromised, but even when members experienced a diminished sense of shared values. Thus, the results call attention to the importance that female supporters attach to their identification with an organization in terms of that organization's values and ethical integrity. Even highly satisfied female supporters of an organization are likely to withdraw support (to a greater degree than their male counterparts) if their identification with the organization is diminished because the organization's ethical integrity is compromised, and even if they experience a loss in shared values with the organization.

These findings concur with many of the studies on gender differences in business ethics, which have found that women hold business activities to a higher ethical standard than men. While in some studies such gender 
differences have proven to be attenuated or not present under certain circumstances, the gender differences that emerged here must be seriously considered.

\section{BIOGRAPHIES}

Susan G. Rozensher is Associate Professor of Marketing at Iona College in New Rochelle, New York. She received her Ph.D. from Columbia University and her teaching and research interests include customer loyalty, marketing research, marketing education, and commercialism in schools.

P. Everett Fergenson is Professor of Marketing at Iona College in New Rochelle, New York. He received his Ph.D. from the University of Massachusetts at Amherst, and his teaching and research interests include business ethics, consumer psychology, sports marketing, and marketing education.

\section{REFERENCES}

1. Ashforth, B. E. and F. Mael: 1989, Social identity theory and organizations, Academy of Management Review, (14) 1, 20-39.

2. Babakus, Emin, T. Bettina Cornwell, Vince Mitchell, and Bobo Schlegelmilch: 2004, Reactions to unethical consumer behavior across six countries, Journal of Consumer Marketing, (21) 4/5, 254-266.

3. Bendall-Lyon, Dawn and Thomas Powers: 2002, The impact of gender differences on change in satisfaction over time, Journal of Consumer Marketing, (19) 1, 10-22.

4. Bhattacharya, C. B., H. Rao and M.A. Glynn: 1995, Understanding the bond of identification: An investigation of its correlates among art museum members, Journal of Marketing (59) 4, 46-57.

5. Bhattacharya, C.G. and S. Sen: 2003, Consumer-company identification: A framework for understanding consumers' relationships with companies, Journal of Marketing, (67) 2, 76-89.

6. Dutton, J. El, Dukerich, J. M. and Harquail, C. V.: 1994, Organizational images and member identification, Administrative Science Quarterly, (39) 2, 239-263.

7. Franke, George, Deborah Crown, and Deborah Spake: 1997, Gender differences in ethical perceptions of business practices: A social role theory perspective, Journal of Applied Psychology, (82) 6, 920-934.

8. Glover, Saundra, Minnette A. Bumpus, Glynda F. Sharp, and George A. Munchus: 2002, Gender differences in ethical decision making, Women in Management Review, (17) 5/6, 217-228.

9. Izraeli, Dove and Eugene Jaffe: 2000, Are there gender differences in the ethics judgments of marketing managers?, International Journal of Value-Based Management, (13) 159-172.

10. Kelly, C. E.: 1990 Bad men speaking well: A case study of political campaign ethics, Annual Meeting of the Eastern Communication Association, Philadelphia, PA. April 19-22.

11. Perrin-Martinenq, D.: 2004, The role of brand detachment on the dissolution of the relationship between the consumer and the brand, Journal of Marketing Management, (20) 9/10, 1001-1022.

12. Petty, G. and Hill, R.: 1994, Are women and men different? A study of the occupational ethic, Journal of Vocational Education Research (19) 1, 71-89

13. Pratt, M.G.: 1998, To be or not to be: Central questions in organizational identification, in Whetton, David A. and Godfrey, Paul C. (Eds.) Identity in Organizations: Building Theory Through Conversations, Thousand Oaks, CA: Sage Publications, 171-207.

14. Rees, P. and H. Gardner: 2003, Best value, partnerships and relationship marketing in local government, International Journal of Non Profit and Voluntary Sector Marketing, (8)2, 143-152.

15. Rowley, J. and J. Dawes: 2000, Disloyalty: A closer look at non-loyals, Journal of Consumer Marketing, (17) 6, 538.

16. Sankaran, Siva and Tung Bui: 2003, Ethical attitudes among accounting majors: An empirical study, Journal of the American Academy of Business, 3(1/2), 71-78. 